\title{
CUERPO Y LIBERTAD. EL EXPERIMENTO NEUROLÓGICO DE LIBET
}

\author{
JACINTO RIVERA DE ROSALES \\ UNED, Madrid
}

\begin{abstract}
RESUMEN: El clásico debate entre determinismo y libertad se ha reavivado con el experimento neurológico de Libet y sus diversas versiones. Algunos han querido ver ahí una confirmación científica e irrebatible del determinismo, o sea, de que la subjetividad y la conciencia no son agentes sino un mero efecto de procesos objetivos neuronales. En el artículo se sostiene que esa interpretación es incorrecta porque olvida un elemento: el proceso de preparación del experimento, y porque no ve otro: el carácter subjetivo del cuerpo propio, pues metodológicamente la ciencia ha de tratar sólo lo objetivo y hacer abstracción de todo otro modo de ser.
\end{abstract}

PALABRAS CLAVE: libertad, determinismo, Libet, cuerpo propio, neurociencia.

\section{Body and Freedom. Libet's neurological experiment}

\begin{abstract}
The classic debate between determinism and freedom has been revived with the neurological Libet experiment and its various versions. Some have wanted to see in it a scientific and irrefutable confirmation of determinism, that is, that subjectivity and consciousness are not agents but a mere effect of objective neuronal processes. The article argues that this interpretation is incorrect because it forgets one point, the process of preparing the experiment, and because it doesn't see another, the subjective nature of the body since, methodologically, science has to deal only with the objective being and must make an abstraction of any another way of being.
\end{abstract}

KEY WORDS: freedom, determinism, Libet, body, neuroscience.

\section{Determinismo y LIBERTAD}

Uno de los debates centrales en la reflexión filosófica gira en torno al tema de si somos libres o si estamos determinados. Según los estoicos todo estaría regido por el Logos, por la ley del universo, una idea que se remonta a Heráclito. Este logos cósmico sería inmanente al mundo, formaría una unidad con la materia y lo determinaría todo. También se le denomina fatum o destino, del que Séneca nos dejó una famosa sentencia: «fata volentem ducunt, nolentem trahunt», es decir, "el destino conduce al que se somete y arrastra al que se resiste» ${ }^{1}$. Esta idea (la del fatum o el destino) ha sido profusamente explotada en las tragedias clásicas, por ejemplo en Sófocles, en Shakespeare o

1 «[...] e invoquemos a Júpiter, cuyo gobierno dirige esta mole del universo, como lo invoca nuestro Cleantes con versos elocuentísimos, que me permito traducir a nuestra lengua siguiendo el ejemplo de Cicerón [...]: "Condúceme, ¡oh padre, señor del encumbrado cielo!, doquiera te plazca: nada me retiene para obedecerte; aquí estoy sin vacilar. Mas suponte que me resista, te acompañaré entre lamentos y, contrariado, soportaré lo que habría podido realizar complacido. Al que está resuelto los hados lo conducen, al que se resiste lo arrastran"» (SÉnECA, Epístolas morales a Lucilio, Carta 107, 11 (= 527 SVF); trad. en Gredos, Madrid, 1989, vol. II, p. 294). Aquí Seneca vierte al latín el fragmento de Cleantes que se encuentra publicado en SVF (Stoicorum Veterum Fragmenta) I, 527 (B. G. Teubner, Leipzig, 1978). 
en Calderón. Es un elemento dramático recurrente: lo predicho tiene lugar, lo quieran o no los personajes. Por mucho que el protagonista desee escapar a su destino, sucumbirá ante él de una o de otra manera. Edipo, intentando evitar el oráculo que le predice que matará a su padre y se casará con su madre, se aleja de aquellos que cree sus progenitores, y eso mismo provoca que en una encrucijada de caminos luche con su verdadero padre biológico, que él no conoce, lo mate y llegue a casarse con su verdadera madre sin que él lo sepa. Fuerzas que ignoramos, superiores e incontrolables, nos dirigen.

El cristianismo y su herencia hebrea trajeron un problema adicional al tema de la libertad, a saber, el de hacerla compatible con un Dios omnipotente y creador ex nihilo de todo, una idea extraña al pensamiento griego anterior. A ello se añadía una dificultad de carácter teológico acerca de la Gracia divina y la salvación. Ya a principios del s. V de nuestra era Pelagio y Agustín de Hipona se enfrentaron muy duramente debatiendo si ante un Dios todopoderoso y su Gracia salvadora podía haber algún sitio para nuestra libertad, o si no resultaba más bien que estábamos ya predestinados por decisión divina. Esto último era lo que pensaba Agustín. Por eso Lutero y los reformadores cristianos tachaban de pelagianos a los seguidores de la Iglesia romana y defendían la idea de un servo arbitrio, un albedrío que, como un caballo, sería montado y guiado o bien por Dios o por el diablo, según Dios lo hubiera dispuesto.

Este Dios cristiano introdujo, sobre todo en la modernidad, a partir del Renacimiento, dos cuestiones en el pensamiento filosófico. La primera fue el tema del mal: ¿Cómo es posible que siendo Dios bueno, omnisciente y omnipotente no evite el mal y el sufrimiento en el mundo? ¿Es que no quiere, o no sabe o no puede evitarlo? Parecía una prueba fuerte contra la existencia de Dios, frente a la cual Leibniz se sintió obligado a escribir su Teodicea o "Defensa de Dios», como abogado que ha de socorrerle ante la evidencia del mal en el mundo.

El segundo asunto fue la libertad: ¿Cómo podemos ser libres, si Dios todo lo ha previsto y determinado, si toda la realidad procede de Él y tiene que ser constantemente conservada por Él para que no desaparezca en la nada, por cuanto que Él es su único fundamento? Puesto Dios, no cabe una realidad o acción que proceda realmente de nosotros, sino que todo es creado y conservado por Él. Esta idea de un Dios creador pensada hasta el fondo ponía en serio peligro la afirmación de una libertad humana. En el Renacimiento, el humanista Lorenzo Valla, en su libro De libero arbitrio $(1436)^{2}$, puso en tela de juicio la posibilidad nacional de compatibilizar nuestra libertad y Dios creador, pues su presciencia es capaz de prever todo futuro.

Al mismo tiempo se abría paso un determinismo de base racional que se inspiraba también en la nueva ciencia. Así, para el aristotélico Pietro Pompo-

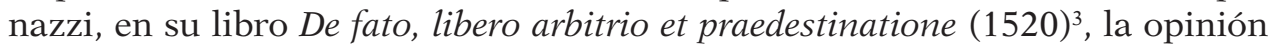

2 Hay una edición bilingüe latín/alemán en Fink, Munich, 1987.

3 Hay edición bilingüe latín/italiano en Istituto Nazionale di Studi sul Rinascimento, Turín, 2004. 
más aceptable filosóficamente era el fatum estoico. No obstante aceptaba la teoría de la doble verdad, la verdad de la fe y la de la razón, a fin de no acabar «como las castañas», en la hoguera de la Inquisición.

Spinoza y Hobbes inauguran en la filosofía el determinismo moderno, nuestro tema. Hay una famosa sentencia del filósofo Spinoza en la que él nos asegura lo mismo y de una manera más tajante que los estoicos, con los que guarda cierta filiación, y que los reformadores protestantes, por cuanto que para él todo lo real no sería sino expresión inmediata y necesaria de Dios, inmediata en el sentido de que la causalidad de la Substancia no es transitiva sino inmanente. A eso se une su admiración por el modo geométrico de explicación y por las nuevas ciencias, lo que hace que el despliegue de la Substancia no sea pensado por ejemplo a la manera artística, como podría suceder en un espíritu romántico, sino con la necesidad propia de la ciencia moderna matematizada. El veredicto de Spinoza reza así: «Los hombres se equivocan al creerse libres, opinión que obedece al solo hecho de que son conscientes de sus acciones e ignorantes de las causas que las determinan. Y, por tanto, su idea de «libertad» se reduce al desconocimiento de las causas de sus acciones, pues todo eso que dicen de que las acciones humanas dependen de la voluntad son palabras, sin idea alguna que les corresponda $»^{4}$. Y en otra parte de su Ética sigue diciendo: «Sueñan con los ojos abiertos» ${ }^{5}$, ya que "no hay en el alma [o mente, mens] ninguna voluntad absoluta o libre, sino que el alma es determinada a querer esto o aquello por una causa, que también es determinada por otra, y ésta a su vez por otra, y así hasta el infinito» ${ }^{6}$. Comprendamos que esta idea de la total determinación de la realidad se le impone a Spinoza únicamente desde la pura razón, a priori, a partir de las exigencias de lo que Kant denominaría la razón pura teórica por llegar a la totalidad y a lo incondicionado, y no por la experiencia, pues de hecho Spinoza tampoco sabe cómo en concreto está todo determinado. En la Carta 23, le dice a Blijenbergh: «Mas si usted me pregunta, además, qué le puede mover a hacer esta obra, que yo llamo virtud, más bien que otra, le digo que yo no puedo saber de qué medio, entre los infinitos [que Spinoza también desconoce], se sirve Dios para determinarle a Usted a esta obra ${ }^{7}$. Entonces resulta que esa ignorancia sobre los hechos no le es impedimento para afirmar la total determinación de lo que nos sucede, pensamos y queremos. Se trata de un principio a priori no controlable por la experiencia, de una petición racional no comprobable. Kant diría que en esto se afirma más de lo que en verdad se sabe, y se convierte en principio real y probado lo que de suyo sólo es un principio ideal de búsqueda científica.

Esto mismo ocurre con el determinista «científico», o mejor dicho con el filósofo que pretende funcionar como científico, según el cual cada una de las

4 Spinoza, Ética II, Proposición XXXV, Escolio, traducción de Vidal Peña en Alianza, Madrid, 2009, p. 157.

5 SpInoza, Ética III, Proposición II, Escolio, trad. 201.

6 SpInoza, Ética II, Proposición XLVIII, trad. 176.

7 Spinoza, Correspondencia, Alianza, Madrid, 1988, p. 213. 
circunstancias determina objetivamente la acción que realizamos nosotros los hombres, por lo que únicamente ella es posible. Pensar que hubiéramos podido realizar otra es algo meramente imaginario, que existe sólo en la mente pero no en la posibilidad real, una ilusión que surge al pensar que en circunstancias distintas habríamos podido hacer otra cosa, por ejemplo, quedarnos sentados o levantarnos de la silla. En el mundo son ciertamente posibles esas dos acciones, pero cada circunstancia determina la acción concreta que llevamos a cabo, nos replica. En verdad, habríamos de decir, él también ignora qué circunstancia llevará a uno o a otro acto, o por qué en incontables momentos y circunstancias diferentes de nuestras vidas seguimos sentados y en otras también muy distintas nos levantamos, de modo que juzga de forma a priori que, suceda lo que suceda, estará ya decidido por las circunstancias objetivas. Su razonamiento está lejos de ser científico, es decir, de apoyarse en una confirmación objetiva y experimental, lo que es un requerimiento también exigido en el mundo subatómico, como le ocurrió recientemente al bosón de Higgs. Otra cosa sería que nos mostrara empíricamente todos los elementos objetivos y empíricos que concurren en una experiencia, y que esos son todos, y cómo ellos conducen necesariamente a que tal persona permanezca sentada en unos momentos sí y en otros no. Pero no es eso lo que sucede, sino que sostiene su afirmación sobre la base de un principio racional teórico, de manera a priori y dogmática, sin esforzarse en demostrarlo científicamente. Por tanto no sabe, sino que se lo imagina.

Para acercarnos plástica e imaginativamente a esta idea determinista, Spinoza nos propone un experimento mental. Si tiramos una piedra al aire, ella se moverá irremediablemente según las leyes físicas del impulso. Pero, y aquí viene el experimento, "conciba ahora, si lo desea -escribe el filósofo en carta a G.H. Schuller-, que la piedra, mientras prosigue su movimiento, piensa y sabe que ella se esfuerza cuanto puede por seguir moviéndose. Sin duda esa piedra, como tan sólo es consciente de su conato y no es de ningún modo indiferente, creerá que es totalmente libre y que la causa de perseverar en el movimiento no es sino que así lo quiere. Y ésta es esa famosa libertad humana, que todos se jactan de tener, y que tan sólo consiste en que los hombres son conscientes de su apetito e ignorantes de las causas por las que son determinados» ${ }^{8}$. Estimo que este ejemplo de la piedra es fallido, incluso falaz, pues oculta justamente aquello que tenía que ser pensado en esta cuestión. Si la piedra tuviera conciencia, y más aún conciencia reflexiva, llegaría también en esa medida al concepto y a la libertad. Si carece de conciencia y no alcanza al concepto es porque no se dan en ella las condiciones de posibilidad de los mismos, la subjetividad

8 Carta 58, trad. 337. Habríamos de distinguir entre la determinación interior de nuestro conato, una necesidad que coincide con la libertad en el sentido spinozista, y la determinación de unos modos finitos por otros, de donde procedería la dependencia y la servidumbre que hay que superar en lo posible mediante el apartamiento de las pasiones tristes, la búsqueda de las ideas adecuadas y la utilidad racional, más la contemplación de todo lo real como expresión inmediata de la Substancia o Dios. 
necesaria, y eso justamente le imposibilita ser libre. El experimento por tanto añade mágicamente la conciencia reflexiva a la piedra sin pensar ni tener en cuenta las condiciones que harían eso posible, de las cuales la piedra carece, y por eso también de libertad. Esto muestra asimismo las limitaciones del razonamiento a priori de Spinoza.

A partir de las ciencias modernas que surgieron en la época del Renacimiento, ese Logos estoico, que todo lo rige, se ha transformado en un determinismo de la razón científica, regido por sus leyes matematizadas y verificadas en la experiencia. Este es el ámbito en el que nos vamos a mover. Las ciencias modernas establecen su saber por medio de leyes que reglamentan y predicen los fenómenos, leyes según las cuales todo estaría determinado, física, química, biológica o neuronalmente determinado. Sobre este punto es emblemática la visión de Laplace: «Podemos mirar el estado presente del universo como el efecto del pasado y la causa de su futuro. Se podría concebir un intelecto que en cualquier momento dado conociera todas las fuerzas que animan la naturaleza y las posiciones de los seres que la componen; si este intelecto fuera lo suficientemente vasto como para someter los datos a análisis, podría condensar en una simple fórmula el movimiento de los grandes cuerpos del universo y del átomo más ligero; para tal intelecto nada podría ser incierto y el futuro,

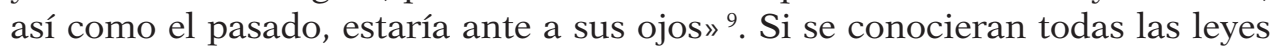
de la naturaleza y la posición e impulso de todos los cuerpos que la componen en un momento dado, entonces se podría predecir todo el futuro con exactitud matemática. En ese caso podríamos orientarnos plenamente en el mundo de los objetos. Ese es el objetivo a donde se dirige el esfuerzo científico y su aplicación técnica, esa es la meta hacia la que quiere ir avanzando el conocimiento teórico en general como a su ideal. Conseguirlo significaría preverlo e incluso dominarlo todo objetivamente. De ese modo sabríamos siempre a qué atenernos, qué hacer, y podríamos cubrir todas nuestras necesidades. En realidad seríamos omnipotentes y conseguiríamos vivir para siempre, evitando las enfermedades y la muerte. Claro que si todo el mundo es igualmente dominado, nosotros, al pertenecer también a ese mundo, quedaríamos integrados en esa malla, convertidos en máquinas, pensados asimismo como meros objetos, a modo de cazadores cazados que caen en sus propias redes, y no tendríamos nada que hacer. Lo que se había planteado en cuanto medio de liberación, al ser totalizado acaba por borrarnos la capacidad de fines que es la libertad. Pero en realidad lo que se tiene entre manos es simplemente un proyecto que nunca llegará a abarcar todo lo real, a la totalidad de los modos de ser ni a lo incondicionado, porque el campo del conocimiento objetivo real sólo alcanza un modo de ser y además ahí tiene un horizonte ilimitado, siempre está in fieri, en proceso; por tanto, en ese determinismo se afirma más de lo que de hecho se sabe.

9 LAPlace, Essai philosophique sur les probabilités, Introduction, Culture et Civilisation, 1967, p. 2. Hay traducción al español en Pierre-Simón de LAPLACE, Ensayo filosófico sobre las probabilidades, Alianza, Madrid, 1989; la cita está en la p. 25. 
El avance espectacular de la ciencia en el saber y en sus aplicaciones técnicas y útiles ha consolidado tanto su prestigio que hoy parece que el único conocimiento verdadero e interesante y el que trae un progreso real al ser humano es el científico ${ }^{10}$. La cuestión es que si todo está determinado ¿qué hacemos entonces con la libertad? ¿Es una mera ilusión, un fantasma como concluyen muchos? Eso nos crearía sin embargo un gran problema y una enorme perplejidad en la vida práctica. Si bien el conocimiento teórico y objetivante nos encamina hacia el determinismo, en el ámbito de las acciones, en el de la moral, el derecho, la política, las relaciones humanas, etc. parece por el contrario que no podemos prescindir de la idea de libertad. Por ejemplo, cuando condenamos a alguien por haber cometido un crimen, lo hacemos porque pensamos que es responsable de sus actos, es decir, que él podía y debía no haberlo perpretado por cuanto que es un ser libre. Dado que suponemos lo contrario, no condenamos al niño pequeño o al loco, al no considerarlos responsables. También cuando decimos a alguien: "tú debes hacer esto», es porque suponemos que podría hacer otra cosa, así como seguir o no seguir nuestro consejo. Asimismo pensamos que moral, jurídica y políticamente todos los hombres son o deben ser libres y ponemos la libertad en el primero de los Derechos Humanos, los que deben regir todas nuestras relaciones, y por eso sostenemos que el sistema político correcto es la democracia, porque pensamos que se apoya o se debe fundar en la libertad de cada uno. Todos los ideales de convivencia, al menos en Occidente, están basados en el concepto de libertad y en contra de la esclavitud, opresión o tiranía como principios de organización justa y racional. En el 2013 salió a la luz la película Doce años de esclavitud, sobre la autobiografía de un negro norteamericano del s. XIX, en donde ese anhelo de libertad está expresado con especial fuerza y atrapa nuestra emoción.

Por consiguiente, aquí entramos en contradicción con nosotros mismos: cuando queremos objetivar, manipular, conocer objetiva y científicamente, pensamos de manera determinista el mundo y a nosotros mismos, pero a la hora de actuar individualmente o en convivencia con los otros nos ponemos como seres libres y creemos que lo correcto es tratar a los otros como tales a diferencia de como tratamos las cosas. Tenemos por tanto ante nosotros dos perspectivas, la teórica y la práctica, y el problema surge cuando el ámbito de la determinación teórica pretende abarcar la totalidad de lo que es, pues entonces su determinismo viene a abolir la otra perspectiva, a anular la libertad, a tacharla de pura ilusión y engaño; lo reduce todo a la objetividad, al modo de ser del objeto, pero en realidad lo que hace es convertir los principios metodológicos que guían su búsqueda e investigación en principios que ya habrían

10 Dejemos a un lado la cuestión sobre si la física cuántica ha puesto en tela de juicio ese determinismo mecánico del mesocosmos, y nos ha abierto a un mundo estadístico, de variadas posibilidades, que seguramente sería suficiente para nuestra libertad finita, pues ésta se encuentra también ante un abanico limitado de posibilidades. Lo dejamos porque no es ése el universo en el que se mueve la defensa del determinismo que arranca del experimento de Libet. 
alcanzado a conocer toda la realidad, tanto la conocida como la que de hecho no lo es. Por el contrario la perspectiva práctica sólo demanda limitar el determinismo, no abolirlo, pues no estamos hablando de una libertad omnipotente que creara el mundo y lo configurara según su deseo, sino de una que es finita y que por tanto precisa que el mundo le sea dado. Además necesita que ese mundo no sea caótico sino que se rija por leyes, que haya regularidades objetivas, a fin de poder orientarse en la planificación de sus fines y que las cosas le sirvan de medios, pues en caso contrario no sabríamos cómo actuar, cómo manejarlos o movernos entre ellos. Si las cosas se comportaran a cada momento de forma diferente y de pronto la mesa saliera volando, y en otro momento se convirtiera en líquido sin ninguna regularidad, o bien desapareciera, o de cuadrada se hiciera redonda, o se transformara imprevisiblemente en un ser vivo que nos devorara, etc. no sabríamos a qué atenernos, cómo utilizarla, qué hacer con ella. La libertad necesita regularidades, pero también encontrar un espacio ontológico de realidad en el que afirmarse, y por tanto limitar el ámbito del modo de ser del objeto, aquel en el que sería válido el determinismo natural.

\section{El experimento neurológico de Benjamin LiBet}

Decía que el determinismo total es un principio a priori que no se ve validado en la experiencia, en una experiencia empírica real, pues está siempre limitada y se halla recortada en un continuo espacio-temporal-causal. Pero he aquí que en la neurociencia se encuentra una experiencia concreta, delimitada y científicamente controlada que parece confirmar que no somos libres. Se trata del experimento neurológico de Benjamin Libet $^{11}$ con el que muchos quieren zanjar "científicamente» esta cuestión y negar la libertad, un asunto que yo consideraría como estrictamente filosófico (lo plantee quien lo plantee), es decir, no decidible por un método y medios científicos. De ese experimento

11 Puede leerse su propia explicación en Liвet, B., «Unconscious cerebral initiative and the role of conscious will in voluntary action», en la revista The behavioral and brain sciences 8 (1985), 529-566. Libet, B., «Do We Have Free Will?», en Journal of Consciousness Studies 6, No. 8-9 (1999), pp. 47-57. Haggard, P., LiBet, B., «Conscious Intention and Brain Activity», en Journal of Consciousness Studies 8, 11 (2001), pp. 47-63. Puede verse también SEarle, J. R. Libertad y neurobiología. Reflexiones sobre el libre albedrío, el lenguaje y el poder político, Paidós, Barcelona, 2005. Amengual, G., Antropología filosófica, BAC, Madrid, 2007, pp. 257277. Rubia, F. J., El fantasma de la libertad. Datos de la revolución neurocientífica, Crítica, Barcelona, 2009. KLEmm, W. R, «Free will debates: Simple experiments are not so simple». Advances in Cognitive Psychology, 6 (2010), pp. 47-65, http://www.ncbi.nlm.nih.gov/pmc/ar ticles/PMC2942748/. Baciero Ruiz, F. T., "Algunas reflexiones sobre los experimentos «Tipo Libet» y las bases del determinismo neurológico», en Thémata. Revista de Filosofía 46 (2012), pp. 259-269. Fuster, J., The Neuroscience of Freedom and Creativity, Cambridge University Press, 2013; trad. Cerebro y libertad. Los cimientos cerebrales para nuestra capacidad para elegir, Ariel, Barcelona, 2014. Álvarez Díaz, J. A. «Libertad y ética: el trabajo de Benjamin Libet». Revista Bioética 22 (2014), 434-40. 
surge la pregunta: ¿Serán las neuronas las que determinan por sí mismas y objetivamente lo que hacemos?

Previamente los neurólogos alemanes Kornhuber y Deecke habían comprobado que los movimientos corporales conllevan una alteración del campo eléctrico en el cerebro, la cual puede medirse en la corteza cerebral. De este hecho partió el experimento de Libet en 1983, que después ha sido repetido múltiples veces y perfeccionado por Patrick Haggard, Martin Eimer y John Dylan Haynes entre otros, conduciendo esencialmente siempre al mismo resultado. ¿En qué consistía? Los sujetos experimentados tenían que apretar un botón cuando ellos lo decidieran o bien cuando se lo indicaran los experimentadores y comunicar en qué momento lo habían decidido. La variable o magnitud esencial en este experimento era el tiempo que mediaba entre tres momentos de ese mismo acto: $1^{\circ}$ el de la alteración eléctrica neuronal en el cerebro debida al movimiento corporal del dedo, que se determinaba mediante un electroencefalograma, $2^{\circ}$ el de la toma de conciencia de querer hacer el movimiento con el dedo y apretar el botón que, como hecho subjetivo, sólo se podía conocer por el informe del experimentado, y $3^{\circ}$ el tiempo del movimiento físico-muscular del dedo apretando el botón, para lo cual se conectó un reloj a la señal eléctrica producida por el movimiento muscular del dedo, una señal que era detectada por un electromiograma. A fin de comprobar con precisión el tiempo se usó un reloj capaz de medir milisegundos.

¿Cuáles fueron los resultados? Como cabía esperar, la conciencia de querer mover el dedo precedía al movimiento real del mismo, exactamente en 204 milisegundos (2 décimas de segundo). En realidad este tiempo es tan mínimo que la conciencia común no lo percibe y le parecen sucesos simultáneos, es decir, que ella piensa que aprieta el botón en el mismo momento en el que quiere hacerlo. Algo más sorprendente resultó ser el hecho de que la conciencia de mover el dedo precedía al movimiento real del mismo en 86 milisegundos (casi 1 décima de segundo), o sea que vivenciamos nuestras acciones casi una décima de segundo antes de que éstas sucedan, seguramente porque una décima de segundo antes hemos tenido la conciencia de decidir el hacer esa acción. Todo esto, sin embargo, lo vivimos como simultáneo porque no percibimos subjetivamente la diferencia temporal que hay en una o dos décimas de segundo, no vivimos tan rápido ni parece ser que lo necesitemos biológicamente. En todo caso ambos datos nos indican que es la conciencia la que precede a la acción y en consecuencia podríamos seguir pensando que es la conciencia la que determina el acto, un dato que avalaría la existencia de la libertad, o sea, que es el sujeto el que dispone la acción según sus intenciones y sus fines.

La sorpresa surgió ante una tercera medición según la cual la actividad cerebral era siempre anterior a la conciencia de querer mover el dedo. Si el sujeto experimentado tenía que hacer el movimiento del dedo cuando el experimentador se lo indicaba, la actividad cerebral sucedía 350 milisegundos antes (550 milisegundos antes que el movimiento del dedo), posiblemente porque la orden venía de fuera y la acción se hacía más automática. Si el movimiento lo hacía el sujeto libremente, es decir, si él determinaba cuándo llevarlo a cabo, entonces 
necesitaba más tiempo de planificación previa y la distancia temporal entre la actividad cerebral y la conciencia de querer mover el dedo se alargaba a 825 milisegundos, y el movimiento cerebral precedía en 1025 milisegundos al movimiento del dedo. Por consiguiente, los procesos neuronales que conducían a la realización del acto eran anteriores a la intención consciente de realizarlo, de modo que ésta no podía ser la causa de aquéllos, pues pensamos que la causa ha de ser anterior a su efecto. El experimento científico mostraba que es el cerebro, sus neuronas, el que inicia o «decide» iniciar la acción, la cual comenzaría entonces de manera inconsciente, y la conciencia de querer hacer la acción o conciencia de libertad no sería causa u origen de la acción, sino algo a su vez causado y provocado por la actividad cerebral y efecto de la misma, un eslabón intermedio en la cadena de sucesos que desembocan en la realización de la acción, la de apretar el botón con el dedo en este caso concreto. La acción no estaría causada por la conciencia o el querer, sino que vendría provocada en último término por las neuronas, las cuales darían lugar a su vez a la conciencia del querer. La conciencia, el querer y la ilusión de libertad no serían por tanto sino efectos concomitantes de las neuronas; éstas se crean su propio espectador con la falsa conciencia de ser actor.

Pues bien, lo que sucede en este acto tan simple de apretar un botón es lo que sucedería en cualquier acción real que hagamos y cabría extenderlo a todas nuestras acciones que suponemos libres. Luego la sensación de libertad, la creencia de que nuestra conciencia determina nuestros actos reales, es puro espejismo, un fantasma del cerebro, dado que en el experimento se comprueba que son las neuronas, en sus procesos físicos, meramente mecánicos y no subjetivos o volitivos, las que fijan lo que hacemos y que la conciencia es una de sus consecuencias. La subjetividad sería pues un epifenómeno irrelevante para el hecho real, para nuestra realidad, pues se limitaría a ser un mero espectador, que además vive en el engaño, hasta que una conciencia científicamente informada le saca de ese error. Incluso entonces la conciencia común seguirá percibiendo lo mismo, que es ella la que actúa, pero ya sabría gracias al experimento científico que no es así, de igual modo que seguimos viendo partido el palo que introducimos oblicuamente en el agua, aunque somos capaces de rectificar en el pensamiento esa ilusión óptica producida por la conjunción de dos medios conductores distintos de la luz: el aire y el agua.

Así razonan muchos ante el experimento de Libet, contentos de poder demostrar que no son libres. No obstante, el propio Libet dejaba un resquicio a la libertad de la conciencia, pues ésta sería capaz de inhibir la acción en las 2 fracciones de segundo en las que ella precede al acto. Claro que en esa posición de Libet la libertad no tendría capacidad de proponer fines, carecería de iniciativa creadora. Viviríamos una vida mecánica, a la que sólo podríamos poner ciertos márgenes. Además no se nos explica cómo esa voluntad consciente de inhibir la acción podría, ahora sí, actuar en el cerebro y convertirse en actividad neuronal, cuando parece ser que es ésta la que precedería a todo acto de querer, y por tanto también al acto de inhibir esa acción concreta, el cual de nuevo tendría que ser decidido por las neuronas y no por una ilusoria libertad subjetiva. 
Esa sería asimismo curiosamente la posición de Spinoza. Según él y al contrario de lo que sostenía Descartes con su teoría de la glándula pineal, todo lo que sucede en el mundo corporal está hecho y regido por los cuerpos, no por las ideas, pues «ni el cuerpo puede determinar al alma a pensar, ni el alma puede determinar al cuerpo al movimiento ni al reposo, ni a otra cosa alguna (si la hay)», dado que son modos de dos atributos diferentes. Pero entonces, ¿todo lo que hace el hombre en el atributo extensión, los edificios que construye, los libros que escribe, la música que compone, los sonidos o lenguaje que emite, las sonrisas que lanza, los cuadros que pinta, la ciencia y la filosofía que queda expresada en el mundo físico, etc. todo eso ha de ser comprendido como efecto exclusivamente de los cuerpos, al igual que sostienen los intérpretes deterministas del experimento de Libet? Spinoza no se arredra tampoco frente a todas esas consecuencias: «Nadie, hasta ahora, ha determinado lo que puede el cuerpo, es decir, a nadie ha enseñado la experiencia, hasta ahora, qué es lo que puede hacer el cuerpo en virtud de las solas leyes de su naturaleza, considerada como puramente corpórea, y qué es lo que no puede hacer salvo que el alma lo determine. Pues nadie hasta ahora ha conocido la fábrica del cuerpo de un modo lo suficientemente preciso como para poder explicar todas sus funciones, por no hablar ahora de que en los animales se observan muchas cosas que exceden con largueza la humana sagacidad, y de que los sonámbulos hacen en sueños muchísimas cosas que no osarían hacer despiertos [...]. Dirán, empero, que no es posible que de las solas leyes de la naturaleza, considerada como puramente corpórea, surjan las causas de los edificios, las pinturas y cosas de índole similar (que se producen sólo en virtud del arte humano), y que el cuerpo humano, si no estuviera determinado y orientado por el alma, no sería capaz de edificar un templo. Pero ya he mostrado que ellos ignoran lo que puede el cuerpo, o lo que puede deducirse de la sola consideración de su naturaleza [...]. De modo que la experiencia misma [que hacemos cosas de las que nos arrepentimos], no menos claramente que la razón, enseña que los hombres creen ser libres sólo a causa de que son conscientes de sus acciones e ignorantes de las causas que las determinan y, además, porque las decisiones del alma no son otra cosa que los apetitos mismos [...] tanto la decisión como el apetito del alma y la determinación del cuerpo son cosas simultáneas por naturaleza, o, mejor dicho, son una sola y misma cosa. [...] Así pues, quienes creen que hablan o callan o hacen cualquier cosa por libre decisión del alma, sueñan con los ojos abiertos» ${ }^{12}$.

Aquí de nuevo la ignorancia parece prestarnos mejor servicio en contra de la conciencia común que el saber. De suyo, partiendo de esas premisas, tendríamos más bien que limitarnos a decir que no conocemos lo que puede un cuerpo, pero no que sabemos que el cuerpo sin conciencia ni libertad y por sus solas leyes es capaz de hacer todo eso mecánicamente y que ahí no juega ningún papel la finalidad de la subjetividad y de la libertad. Tendríamos que quedarnos

12 SPINOZA, Ética III, Proposición II, Escolio, trad. 197-201. 
sin más en la confesión de la ignorancia hasta mejor ocasión. Además, en esto cabría disentir de la idea de que los animales y los sonámbulos y los apetitos carezcan de conciencia y sean meras máquinas, como podría pensar Spinoza en cuanto discípulo de Descartes, pues la conciencia no se reduce a la conciencia reflexiva, sino que ésta es propiamente la punta del iceberg con respecto a la subjetividad en su conjunto, como después diré.

\section{LA CONCIENCIA DE SER LIBRE}

Vamos a suponer que este experimento de Libet cumple con los estrictos requisitos y parámetros científicos, aunque no ha estado exento de críticas en ese sentido. Pero parece ser que todos los experimentos realizados en esa dirección concluyen en la anterioridad del movimiento de las neuronas respecto a la conciencia, ése es el punto que aquí ha de ser analizado. ¿Es correcta la conclusión e interpretación deterministas? Éstas sentencian que la decisión de apretar el botón no la lleva a cabo el sujeto consciente, su voluntad o su conciencia, sino las neuronas, así que estaríamos determinados por ellas y el sujeto no sería responsable de sus actos. ¿Es esto así? Yo pienso que no, incluso siguiendo y estudiando escrupulosamente el mismo experimento de Libet no sería esa la inferencia correcta que de ahí se sigue. Pensar que él nos lleva a un resultado determinista, que anula el carácter originario de la subjetividad y de la libertad, reposa en realidad en un análisis parcial y limitado de lo que allí mismo sucede, en un examen y razonamiento que no ve y se olvida de elementos esenciales que hacen posible ese suceso.

En efecto, en esa interpretación determinista del experimento se contempla tres momentos esenciales: la actividad cerebral, la conciencia de querer actuar y la acción de mover el dedo. En este análisis $\left(1^{\circ}\right)$ se olvidan de un cuarto momento, esencial para todo lo que sucede, siendo además el primero en la sucesión temporal, a saber, el proyecto consciente de hacer el experimento, anterior a la actividad cerebral. Pero además $\left(2^{\circ}\right)$ no ven la subjetividad prerreflexiva del propio cuerpo humano en esa actividad cerebral, algo que necesaria y metodológicamente se escapa a su perspectiva científica objetivante, como no podemos percibir en un cuarto lo que previamente y por principio (metodológico) hemos echado fuera de él. Para explicar y comprender esto, aclaremos y preguntémonos primero, cómo es que tenemos conciencia de que actuamos libremente, es decir, por qué pensamos que estamos obrando nosotros y que eso que estamos haciendo no es un simple movimiento mecánico y objetivo de algo independiente de mí. ¿Por qué poseemos conciencia de libertad, de que somos nosotros los que consciente e intencionadamente realizamos nuestros actos? Gracias a ese saber discriminamos entre los fenómenos realizados por mí y aquellos que no dependen de mi voluntad. Yo no me creo responsable de muchas cosas que suceden en el mundo, por ejemplo de que exista la Luna o aquel río o las distintas especies animales o las acciones de los otros seres humanos. 
$\mathrm{Ni}$ siquiera me siento responsable de sucesos que ocurren en mi cuerpo, por ejemplo de la circulación de mi sangre o de la digestión, del crecimiento de mi pelo o las múltiples funciones del hígado, sino únicamente de los actos que llamo «míos». ¿De qué depende esa atribución, que es aquí lo que se discute? ¿es ella una mera ilusión de la conciencia?

De nuestra autoría en el actuar hay una conciencia que podríamos llamar ideal (moral) y otra real (corporal), y esta última es la que propiamente nos interesa para nuestro asunto. La primera es la conciencia de que debemos ser libres, mientras que la segunda lo sería de que somos nosotros los que de hecho estamos actuando. La conciencia ideal de que somos libres y de que estamos llamados a realizar esa libertad en nuestras acciones es lo que se denomina conciencia moral, un saber que somos responsables, sujetos de deberes y de derechos; sólo a los seres libres y en la medida en que su subjetividad llega a la conciencia reflexiva o están llamados a llegar a ella se les puede exigir deberes y reconocerles derechos, pues estos únicamente pueden ser establecidos en el ámbito universal del concepto. Es lo que Kant denomina «razón práctica», una conciencia que se extiende al ámbito de lo moral, lo jurídico o del derecho, lo político, pero que también hace oír su voz en las labores pragmáticas y técnicas, e incluso en nuestro pensar e investigar, o sea, en todas nuestras acciones reales e ideales. La llamo «conciencia ideal» porque el actuante puede no tenerla en cuenta, o sea, cabe la posibilidad de que no sea realizada, pero sus resultados serían entonces un mundo esclavizado e injusto en el que esa libertad va siendo en esa misma medida destruida, imposibilitada. Por tanto, el hecho de que no se realice o no tenga efectos no descalifica a esa conciencia como algo ilusorio y falaz, como un fantasma, sino que sucede lo contrario, a saber, que el estado del mundo es en ese caso descalificado por injusto e inmoral. Sobre ese presupuesto y esos ideales de libertad y justicia se basa todo nuestro discurso crítico cuando reprobamos los actos de los hombres y de los Estados que no los respetan.

Ahora bien, para enfrentarnos directamente a la interpretación determinista del experimento de Libet, hemos de recurrir a la exploración de la conciencia real (corporal) de nuestras acciones, que es el ámbito en el que se mueve dicho experimento, o sea, hemos de analizar la conciencia de que soy yo quien está haciendo esto y no lo otro, de que soy el responsable de algunos fenómenos del mundo y no de otros muchísimos, de que somos actores de nuestras acciones y no meros espectadores. Ahora nos preguntamos, ante el experimento de Libet, por nuestra conciencia real, efectiva, sobre cómo sabemos y podemos afirmar que somos nosotros los sujetos agentes de esa acción de apretar el botón y si el acto que hacemos es realmente nuestro en cuanto seres conscientes. ¿Cómo sucede eso? ¿Cuáles son las condiciones de posibilidad de que me arrogue la autoría de un acto como siendo mío? Dos son fundamentalmente esas condiciones, es decir, esa conciencia efectiva de realidad surge por dos elementos: $1^{\circ}$ por el concepto o fin o programación que queremos realizar, y ese sería el elemento reflexivo, y $2^{\circ}$ que esté sucediendo o haya sucedido eso mediante mi cuerpo, por medio de mi cuerpo sentido como propio o como nuestro gracias 
al cual voy traduciendo y realizando en el mundo objetivo todo aquello que he programado en mi concepto de fin, lo cual constituye el elemento prerreflexivo. En la acción nuestra, que es a la vez objetiva y reflexivamente consciente, esos dos momentos han de estar presentes y ser sintéticamente unificados. Esos son, por lo demás, los dos elementos que no han sido tenidos en cuenta en la interpretación determinista del experimento de Libet.

a) Soy consciente de mi acción como siendo mía en primer lugar por la autoconciencia en general. Pero de este acto en cuanto que es éste en concreto, por ejemplo el de apretar este botón y precisamente en este momento, sé que es mío gracias al concepto que tengo del fin que ahora persigo, el cual va determinando todo lo que sucede, todo lo que voy haciendo. Todas las acciones conscientes, reflexivamente conscientes, que emprendemos se encuentran formuladas en un concepto particular, el cual es expresión de la voluntad en la conciencia reflexiva. Por ejemplo, pongamos que quiero asistir a una conferencia, entonces el fin o concepto de fin que tengo ahora es: «quiero asistir a la conferencia $\mathrm{X}$ », que la dará tal persona, a tal hora y en tal sala, pues el tema me interesa y asimismo la persona que va a desarrollarlo. Con toda probabilidad ese concepto o fin formará parte de otro más amplio que puede ser por ejemplo: estoy estudiando eso mismo en la Universidad, o estoy escribiendo sobre ese tema, etc. Este propósito estará integrado a su vez en otro aún más global, por ejemplo el de una carrera o una profesión, y así sucesivamente hasta poder formular un proyecto global o sentido de nuestra vida, o sea, qué deseo hacer con o en mi vida (por ejemplo, ser profesor de filosofía de una universidad e investigar tales asuntos), que sería ciertamente una de las tareas mayores para nuestra reflexión y un modo de responsabilizarnos de nosotros mismos. Una persona lista e inteligente es la que se propone los fines más adecuados para él, en sus circunstancias, posibilidades e intereses. Una persona hábil y disciplinada es aquella que es capaz de ejecutarlos de una manera solvente y eficaz.

Así pues, formulamos ese fin o concepto concreto: «quiero asistir a esa conferencia». Ahora bien, este concepto/fin, como todo concepto, no tiene el modo de ser de un objeto, pues no puede ser doblado, pesado, cambiado de lugar, comido o partido, arrojado o extendido sobre una mesa, etc. Tiene pues otro modo de ser, un modo de ser subjetivo e ideal. Aristóteles nos indica que el ser se dice de varias maneras, y la filosofía tiene ante sí la tarea de pensarlas, distinguirlas y conjuntarlas, examinar sus diferencias y establecer su unidad. Las ciencias no tienen esa misión, ellas únicamente se mueven en el modo de ser de lo objetivo, y eso es además lo que metodológicamente deben hacer. Por eso cuando su perspectiva se totaliza y se dice que sólo existe el modo de ser de lo objetivo y que únicamente él es real, entonces se olvida la abstracción y limitación metodológica que dio lugar a la ciencia, y esto es lo que conduce al determinismo total. Hay que tener en cuenta que, 
cuando se habla de la totalidad de lo real, ya no se está haciendo ciencia, sino filosofía, una reflexión filosófica que no debe olvidar la limitación ontológica del conocimiento científico. Pues bien, es esa idealidad del concepto de fin, esa subjetividad, la que determina todo lo que va a sucediendo; en nuestro caso concreto que yo me arregle para salir a la calle, que salga a tal hora y no a otra, que coja esa dirección y ese medio de transporte y no me dedique a pasear por el parque, que entre en esa sala donde van a dar la conferencia y no me quede en una cafetería, etc. Establece todas mis acciones necesarias para la ejecución de ese concepto, decreta cuándo empiezo y cuándo termino, cuándo ha sido conseguido el objetivo y comienzo con la realización de otro fin, por ejemplo el de ir a cenar algo con los amigos que asistieron a esa conferencia, el cual delimitará una nueva serie concreta de acciones mías.

En consecuencia, cuando actuamos reflexivamente seguimos y nos guiamos por medio de un concepto. El concepto-lenguaje, que es lo que nos diferencia de los animales, es el que nos abre el ámbito de la conciencia reflexiva y de la libertad. Consideramos entonces que somos nosotros los que actuamos y no los objetos desde sí mismos, porque todo lo que vamos haciendo y experimentando ocurre según lo planificado y determinado en el concepto o fin que nos hemos propuesto. Por eso pensamos que esas acciones son nuestras acciones y no las de una máquina o mera cosa, porque las acciones siguen las instrucciones de una idealidad pensada, programada y querida previamente, y eso es el concepto de fin.

Pues bien, de esto es de lo que se han olvidado aquellos que del experimento de Libet concluyen que no somos libres, sino que son las neuronas las que deciden qué hacer y las que actúan. Olvidan que lo primero no ha sido la acción de las neuronas, es decir, esa actividad cerebral y objetiva que condujo al sujeto experimentado a apretar el botón, sino la programación del experimento, una idealidad o concepto o fin libre y reflexivamente elaborado y después ejecutado. El sujeto experimentado ha apretado el botón y sus neuronas han actuado o reaccionado así y no de otra manera porque conscientemente se había planificado durante días o meses o años que había de pulsarlo así, dado que ése era el propósito diseñado por el concepto o fin o idealidad que le había guiado hasta ahí, hasta esa sala y en ese momento. Las neuronas habrían por el contrario mostrado su iniciativa, la que les asigna la interpretación determinista, es decir, habrían mostrado que eran ellas las que mandaban, las que decidían y no el sujeto y su conciencia, si en vez de haber puesto en marcha la corriente cerebral que conduce a apretar el botón, hubieran provocado otra que empujara al sujeto experimentado por ejemplo a bailar, o a que se levantara y encendiera un cigarrillo, y el individuo sorprendido, porque viera que su cuerpo está llevando a cabo acciones que él no se había propuesto, dijera: «Pero si yo venía aquí a apretar el botón y de pronto mi cuerpo se me ha independizado y me ha puesto a bailar o a encender un cigarrillo, y no era eso lo que yo tenía pensado hacer aquí y 
ahora». Se sentiría atrapado en su cuerpo como siendo ahora algo extraño, y no como siendo su propio cuerpo, excepto por su identidad física ${ }^{13}$. Pero no es esto lo que acontece en el experimento de Libet, sino que lo que sucede es lo que estaba previamente planificado de manera conceptual y reflexiva. Todo transcurre conforme a esa idealidad pensada en la medida en que no haya fallos, que se considerarían justamente como fallos porque no han salido según lo planificado. No son las neuronas las que determinan en último término que el sujeto experimentado apriete ese botón en tal momento determinado, aunque ellas son ciertamente un eslabón necesario en este proceso e incluso en la planificación, sino el concepto o fin o programación anterior del experimento, el objetivo de llevarlo a cabo, la idealidad largamente elaborada de «voy a hacer ese experimento para ver si...»; ella es la que determina que las neuronas tengan esa actividad y no otra. Ha sido la idealidad subjetiva en cuanto concepto o fin la que ha establecido que tal persona experimentada se le lleve a tal sala y no a la playa o a la montaña, se le coloque un encefalograma y un mielograma y no un sombrero o un paraguas, se le haga sentar en esa silla y no en el sofá de su casa, etc. Las neuronas no deciden, sino que ejecutan lo decidido, lo previamente planificado ideal y subjetivamente, libremente, por los sujetos que después pueden decir: «Hemos hecho tal experimento y ha resultado que...». Aunque no todo lo que precede determina lo subsiguiente, al igual que la noche no es la causa del día, aquí podemos asegurar que sí, pues coincide con lo planificado y cambia si se modifica lo proyectado y en ese mismo sentido. En caso de que no fuera así, estaríamos completamente desorientados y no sabríamos qué hacer. En realidad no existiríamos como seres conscientes al

13 El síndrome de Tourette es un ejemplo de independencia de las neuronas, de tal manera que el individuo no controla su cuerpo, y naturalmente eso le causa un grave problema. Si mi cuerpo ejecuta acciones que no tengo pensadas o incluso no quiero, puede ser que eso suceda por un fallo orgánico o neurológico o bien porque actúe según impulsos inconscientes, de la conciencia prerreflexiva. En ambos casos el sujeto reflexivo se sentirá extraño y extrañado en ese cuerpo y detectamos que hay un fallo que corregir. La habilidad es la capacidad de controlar el propio cuerpo siguiendo el plan, el concepto, el fin propuesto. Eso requiere ejercicio, juego y entrenamiento, todos ellos conducidos por un concepto, por un plan. Es un fin primordial de la educación, también de la educación física, que el niño sea capaz de realizar las tareas que le proponen y que se propone, tan sencillas como: «Vamos a comer, que ya está preparada la cena», y el niño es capaz de realizar ese requerimiento, que es anterior al movimiento de sus neuronas tendentes a realizarlo. Sin esa habilidad de mover y manejar su cuerpo siguiendo conceptos, no seríamos capaces de hacer las cosas que queremos y deseamos, de cubrir nuestras necesidades, y estaríamos abocados a la muerte. El dominio reflexivo del cuerpo forma parte de la educación, por ejemplo en los oficios manuales, o en el deporte, pero también a la hora de saber y poder escribir un ensayo académico, ya sea a mano o en el ordenador. El dominio reflexivo de los movimientos del cuerpo es esencial para nuestro modo de ser humanos. La preparación estratégica de un partido de fútbol por ejemplo intenta determinar previamente por medio del concepto qué hacer físicamente en un momento dado del juego. 
no corresponderle nada real, al no ser esa conciencia nada significativo para la realidad de lo que somos.

b) En segundo lugar comprendemos que ciertas acciones son nuestras porque las realizamos mediante nuestro propio cuerpo, sentido como nuestro gracias a la conciencia corporal. Este es el momento prerreflexivo de la acción. Todo lo que queremos hacer según el concepto o fin que nos proponemos en el ámbito ideal de la conciencia reflexiva, sabemos que lo vamos realizando nosotros también porque lo llevamos a cabo mediante nuestro cuerpo, y no con el cuerpo de otros, como cuando ordenamos a otros que hagan algo planificado por mí. Yo me identifico con mi cuerpo y digo que este es mi cuerpo, que soy este cuerpo, porque $\left(1^{\circ}\right)$ lo siento, siento su placer y su dolor como míos, experimento su movimiento, su esfuerzo, su fatiga, su sueño como siendo yo mismo, o sea, mediante el sentir o el sentirlo. Pero asimismo $\left(2^{\circ}\right)$ porque sus movimientos responden directamente y sin mediación a lo que yo quiero hacer; si decido escribir en mi ordenador, entonces mis brazos, mis manos y mis dedos ejecutan justo aquello que yo me había propuesto o me voy proponiendo escribir, pulsan esas teclas y no otras, en esa sucesión concreta que yo deseo y necesito, incluso corrige los errores que son comprendidos previamente por mí como errores porque no corresponden a lo querido. Esas manos y esos dedos pasan a la realidad objetiva lo que yo había pensado idealmente, convierten en objeto del mundo la idea que yo tenía y quería realizar. El movimiento de ese cuerpo sentido ejecuta inmediatamente (por el experimento de Libet sabemos no obstante que lo hace 2 centésimas de segundo después, un lapso de tiempo que no logramos captar, y por tanto nos parece que son dos hechos simultáneos) aquello que queremos, que hemos proyectado idealmente: escribir, andar, comer, sentarse, girar, mover un brazo, hacer una obra, etc. Esa inmediatez en la ejecución de mi fin es lo que hace que yo considere este cuerpo como mío y que lo distinga de un mero instrumento externo o de la obra que hacen otros por encargo mío. Es en la conjunción de esos dos elementos: el concepto o fin proyectado y el cuerpo sentido ejecutándolo directamente, lo que nos proporciona la conciencia real de que estamos actuando, de que nosotros somos los actores conscientes de ese fenómeno determinado.

\section{El CUERPo y LA CONCIENCIA PRERREFLEXIVA}

Realizamos los fines mediante el cuerpo propio y sentido. Pero para comprender esto hemos de captar además algo que no puede ver la ciencia por su enfoque metodológico meramente objetivo: que un cuerpo sentido no es un mero objeto, sino un sujeto-objeto. Un cuerpo sentido es a la vez subjetivo, pero con una subjetividad que no llega al concepto, a la conciencia reflexiva, 
sino que está provisto de una subjetividad prerreflexiva, parecida a la que pueden tener los animales. Esa es la «sabiduría» del cuerpo. Por eso nos podemos identificar con él y sentirlo como nuestro, a pesar de la distancia que pueda establecer nuestra conciencia reflexiva con respecto al cuerpo y su capacidad de considerarlo como un instrumento o medio para sus fines. Ese sentirlo como mío muestra que el cuerpo no es una mera máquina, pues yo no podría identificarme subjetivamente con algo meramente objetivo, puesto que no habría comunidad en el modo de ser entre ambos.

El cuerpo orgánico es la unidad sintética de lo subjetivo y lo objetivo que necesitamos para comprender la acción objetiva del sujeto consciente. La conciencia reflexiva nace en la distinción expresa (objetivada en el lenguaje) entre concepto y objeto, entre lo subjetivo y lo objetivo, y por eso no logra rebasar esa dualidad en la que se constituye, de modo que cuando piensa el cuerpo o la materia lo objetiva haciendo abstracción de toda subjetividad, y cuando se fija en la subjetividad la capta como una idealidad interior sin materialidad alguna, ambos exteriores entre sí, al modo de los atributos spinozistas, como dos paralelas que no se tocan. La unidad real de sujeto y objeto únicamente la vivimos en la acción real consciente, la captamos y sentimos cuando actuamos según fines gracias al tercer elemento que aquí estamos señalando. Es justamente esa idealidad prerreflexiva del cuerpo orgánico propio, unido sintéticamente con él, la que constituye el punto de enlace entre la subjetividad reflexiva del fin o concepto y la objetividad de la acción física, el puente que hace posible la realización en el mundo de lo que ha sido reflexivamente programado. Eso mismo es lo que acontece en el movimiento neuronal durante el experimento de Libet, que no es un suceso meramente objetivo, sino también subjetivo, de una subjetividad prerreflexiva en unión sintética con la objetividad, que lleva al acto lo que había sido programado previamente en la ideación reflexiva del experimento. Un acto meramente objetivo no podría explicar el surgimiento posterior de la conciencia de querer mover el dedo y de estarlo moviendo; sería una metábasis eis allo genos, porque en la interpretación determinista de ese experimento el cuerpo es pensado primero como carente por completo de conciencia, meramente objetivo y físico, y después de ahí se quiere que salga (mágicamente) la conciencia, que es un modo enteramente diferente de ser a como se ha pensado ese cuerpo. La conciencia y la subjetividad, que se ha apartado del cuerpo mediante la abstracción, como concepto construido, no puede después salir de ahí sin más como un añadido extraño, que por tanto cae necesariamente en la ilusión. Además ¿qué interés biológico o función evolutiva puede tener ese engaño, esa ilusión, ese mero espectador burlado? No podemos pensar que esa función sea por ejemplo la de arrepentirse por la decisión tomada que me ha conducido al desastre y que por tanto me haría estar más atento en mis decisiones siguientes, pues el determinista científico ha convenido que nunca es la conciencia, tampoco por tanto una conciencia que haya aprendido con la experiencia, la que determina la acción, sino los elementos objetivos de cada circunstancia y los procesos físicos de las neuronas. Si el proceso de reflexión sobre las distintas posibilidades o la conciencia de lo que debemos 
hacer entraran ahora en sus cálculos como elementos que determinaran el acto siguiente que llevamos a cabo, entonces ahí la ciencia moderna perdería pie y su determinismo quedaría destruido.

La ciencia tiene que hacer metodológicamente una abstracción de todo lo subjetivo, pues su campo es sólo lo objetivo, pero entonces su visión no puede pretender después abarcar toda la realidad; esa es una tarea de la filosofía, o sea, que quien la aborda se sitúa en el ámbito de la reflexión filosófica, pues ningún método científico abarca la totalidad de lo real. Algo meramente objetivo no puede explicar el surgimiento de la conciencia y del querer, pero sí un suceso objetivo-subjetivo del querer que después es elevado a la conciencia reflexiva justamente como querer (querer mover el dedo) en su lado subjetivo y como movimiento físico del dedo en su lado objetivo, como dos momentos distinguidos de un mismo acto, una distinción entre lo objetivo y lo subjetivo que constituye lo propio de la conciencia reflexiva y que en ella es constitutiva e inevitable.

Mi tesis es por tanto que la subjetividad no se limita a la conciencia reflexiva, la que se mueve en el ámbito de concepto y se expresa en el lenguaje, sino que esta sería como la punta del iceberg que sale a la superficie, a la zona visible para ella misma. Hay asimismo una conciencia prerreflexiva, preconceptual, imaginativa y corporal, que también somos, por debajo del agua (valga esta metáfora espacial), o sea, por debajo de la conciencia reflexiva, sosteniéndola y haciéndola posible. El concepto o fin nos sitúa en el ámbito de la conciencia reflexiva, de la idealidad pensada como tal idealidad, como no siendo aún real sino como proyecto. Somos libres, en el modo de la libertad humana, cuando nos dirigimos por un concepto, por una idealidad pensada, y no como simples efectos de una causa material, sobre todo cuando el concepto último o marco que nos da la pauta definitiva es el mismo concepto de libertad o ley moral. El cuerpo por su parte nos coloca en el ámbito de la objetividad, de la acción o movimiento reales. Pero un cuerpo o movimiento meramente físico, sin idealidad, es una acción puramente mecánica y no libre, no es una acción de un sujeto, y una idealidad o concepto sin acción real es un darle vueltas a la cabeza sin decidirse a actuar y ser libres, un callejón sin salida, sin realización.

Ambos tipos de conciencia, la reflexiva y la prerreflexiva, tienen a su vez múltiples niveles y manifestaciones. Dentro de la conciencia reflexiva distinguimos a los seres humanos que están bien despiertos y lúcidos de aquellos que van más bien distraídos y no se dan cuenta de casi nada, los que son agudos y capaces de una comprensión mayor y aquellos más romos que no logran captar bien lo que les está sucediendo o se le está explicando porque no consiguen reflexionar con claridad. Tal vez una mayor escala y diferencia de niveles podemos encontrar en la conciencia prerreflexiva, pues su campo es aún mayor y más difuso. No es lo mismo la imaginación creadora del genio artístico que la conciencia del animal, y en esta no es igual la que puede tener un chimpancé que la de una medusa. De igual modo lo que normalmente se llama «inconsciente» es una conciencia prerreflexiva, y por eso un contenido suyo pero negado en la conciencia reflexiva puede producir neurosis, pues sería un contenido 
a la vez sabido y no sabido, sabido en un nivel prerreflexivo e ignorado en el reflexivo, tanto que este ni siquiera percibe el rechazo o negación de que ese contenido llegue a la conciencia conceptual, con la que el sujeto se identifica y construye la imagen que tiene de sí, porque le sería muy doloroso e insoportable. Por eso dicho contenido o experiencia negada opera desde el saber prerreflexivo, produciendo una distorsión en el sujeto. Si no fuera en absoluto sabido, no provocaría ningún problema en el sujeto consciente. La cura o solución a esa contradicción interna al sujeto mismo consiste en romper esa barrera inconsciente entre la subjetividad prerreflexiva y la reflexiva, restablecer la conexión y ponerlas en armonía. Ser es para el sujeto una tarea de síntesis o unificación sintética de la multiplicidad de niveles de conciencia, deseos, necesidades, instancias que requieren su atención, etc. El sujeto tiene que configurar una síntesis armónica con esa multiplicidad que se encuentra en tensión, a veces en pugna, y exigiendo cada una del sujeto su tiempo y su energía, que son sin embargo finitos y limitados. Cada uno de nosotros somos muchos, y con esa multiplicidad hemos de construir una unidad, una obra de arte.

Evolutivamente las conciencias más desarrolladas y complejas son posteriores y surgen apoyándose en las anteriores. Pero el salto mayor, la mayor ruptura se produce entre la conciencia prerreflexiva y la reflexiva o conceptual, que inaugura un nuevo mundo: el mundo cultural y libre del ser humano, del concepto y del lenguaje. En esa ruptura que se produce en el surgimiento de la conciencia reflexiva se pueden reconocer ciertas transiciones en el sentido de que, una vez hecha, van apareciendo y desarrollándose poco a poco sus diferentes modos: mitología, religión, arte, filosofía, ciencia, técnica, organización jurídica de la comunidad, etc. Aún hoy estamos en medio de ese despliegue, que tiende a ser ilimitado, como lo es el horizonte del concepto. Por consiguiente, la conciencia reflexiva presupone siempre la prerreflexiva, como en la acción que se lleva a cabo en el experimento de Libet, pues se alza sobre ella como sobre una atalaya, y no puede darse sin ella por ser su conditio sine qua non, no su fundamento, pues éste sería propiamente la autoconciencia, que hace posible toda conciencia (en cualquiera de sus niveles reflexivos y prerreflexivos) y por tanto también la unidad de esa pluralidad, la unidad del sujeto. Incluso el más sublime o el más abstracto de los pensamientos está posibilitado por la conciencia prerreflexiva, unida a la actividad neuronal de aquel que lo está pensando y su conciencia corporal de estarlo pensando. No habría nada ideal (pensar un concepto o un fin) sin algo real que le sirva de base, pero no de fundamento, pues no podríamos decir que la verdad de nuestro pensamiento, la validez de nuestras reflexiones o juicios de valor o de que afirmemos que $2+$ 2 son 4, reposa y se fundamenta en nuestras neuronas, aunque si éstas no funcionaran bien no seríamos capaces de expresar esos pensamientos.

La diferencia o la ruptura reside en que mientras que en la conciencia prerreflexiva lo subjetivo y lo objetivo forman una unidad en el acto mismo, la conciencia reflexiva surge en la distinción expresa entre ambos aspectos, entre el caso como lo objetivo y la regla como lo subjetivo, de manera que la regla de captación queda comprendida en cuanto tal, es decir, es entendida en su 
modo de ser lógico, y se convierte en concepto. Esa nueva idealidad subjetiva, conceptual, reflexiva, toma cuerpo gracias a la aparición del lenguaje humano (no habría ningún tipo de subjetividad sin un modo adecuado de objetivación, pues la subjetividad no es una cosa transcendente al mundo objetivo y objetivado, no tiene el modo de ser de la cosa, ni de una cosa inmanente ni transcendente al mundo). De esa manera aparece la conciencia reflexiva o conciencia humana, partiendo de la prerreflexiva o animal y diferenciándose a la vez de ella. Esto introduce a la conciencia en el ámbito de la universalidad, que es el horizonte propio del concepto, y en eso consiste la ganancia, en el ilimitado campo que le abre a un mundo inédito. Dicha regla-concepto se comprende como tal en su objetivación gracias al lenguaje, que es objetividad subjetivizada y entendida. Es lo que ocurre y se manifiesta en el juicio, en donde el caso y la regla son distinguidos de manera expresa como sujeto y predicado del juicio respectivamente, y a la vez unidos por medio de la cópula. En virtud de esa distinción expresada reflexivamente, cada elemento queda diferenciado del otro y gracias a la materialidad del lenguaje humano el concepto y la idealidad toma vida propia, de manera que da lugar a un universo del saber y del actuar completamente nuevo, como son el mundo de la cultura y de la libertad humanas.

Pero justamente por esa distinción y distancia respecto al mundo objetivo, por su abstracción del caso y su mera idealidad o carácter lógico, el concepto o fin ideado o conciencia reflexiva por sí solos no pueden actuar directamente en el mundo físico: con el mero pensar reflexivo no modificamos nada en el mundo real objetivo (lo contrario sería un pensamiento mágico), aunque ciertamente le confiere objetividad, significado, interpretación al mundo. Toda realización de un concepto de fin ha de recurrir a la unión previa y originaria de idealidad y objetividad, la que tenía lugar en el cuerpo propio, en el momento prerreflexivo. Por consiguiente - y aquí volvemos a dirigir nuestra atención hacia el experimento de Libet-, cuando queremos actuar y efectuar el concepto de fin que nos hemos propuesto, por ejemplo «ir al teatro» o bien «sentarnos en esta silla y apretar este botón», no podemos quedarnos en el mero pensamiento reflexivo (en la pura idealidad del proyecto), sino que tenemos que salvar la distancia surgida entre la objetividad y la subjetividad reflexiva por la abstracción de la regla en cuanto regla, o sea, la operada en el concepto, y volver a la unión sintética de ambos que se daba en la conciencia prerreflexiva, o sea, en el cuerpo vivido, para realizar en el mundo la idealidad planificada. Conectamos entonces sintéticamente con nuestro cuerpo, con la subjetividad que le constituye y con la que nos identificamos, y actuamos desde ahí. Esa unidad la perdemos de vista cuando reflexionamos, porque la reflexión distingue, separa, contrapone, analiza, focaliza, de forma expresa; en toda conciencia hay distinción, también los animales distinguen entre su cuerpo y el de los otros, entre los de su especie y los de otras especies, pero esa conciencia no está objetivada como idealidad en un lenguaje. Es una unidad que recuperamos cuando actuamos, cuando sentimos en la acción nuestra identidad sintética con el cuerpo, con nosotros como cuerpo. Así se lo aclaraba también Descartes a la princesa Elisabeth en su carta del 28 de junio de 1643: cuando reflexiono sólo puedo ver 
la distinción entre el alma y el cuerpo, y únicamente a través de los sentidos y de la vida percibo claramente su unión ${ }^{14}$.

Eso es lo que ocurre cuando se da la actividad cerebral de las neuronas que llevan a accionar el botón programado en el experimento de Libet. Ahí hay tanto objetividad como subjetividad. Pero el científico no lo puede ver, sólo cabe sentirlo y concienciarlo en primera persona. El científico como tal queda fuera, pues no puede considerar la subjetividad como un elemento a tener en cuenta en la explicación científica, ha de centrarse exclusivamente en la objetividad, debido a que se coloca por principio en la perspectiva objetivante, la de la tercera persona, en la que se puede dominar científica y técnicamente el objeto estudiado, la perspectiva de la heteronomía, la que observa desde el exterior, propia de la conciencia reflexiva, que se construye sobre distinciones: la idealidad del pensar es lo que no es el cuerpo y el concepto de cuerpo o de materia es construido como no conteniendo nada de subjetividad, abstrayendo de él toda idealidad. Cuando decimos «cuerpo» o «materia» los hemos despojado ya de toda subjetividad, no pudiendo entonces dar cuenta del cuerpo vivido y experimentado. Pero eso es un concepto construido por la conciencia reflexiva que no debe valer como el único posible para una conciencia reflexiva avisada, filosófica, sí como el que ha de manejar metodológicamente el científico. Y éste hace bien mientras no pretenda hablar de la totalidad de lo real y de los distintos modos de ser, pues con ello pasaría al ámbito de la reflexión filosófica pretendiendo sin embargo seguir en el de la ciencia positiva. No se daría cuenta entonces de que su concepto de cuerpo es abstracto, unilateral, y de que comete la falacia de considerarlo como siendo toda la realidad que hay y que debe ser captada. Por eso la conciencia posterior de querer y de estar actuando surge ante él de manera mágica y con forma engañosa, pretendidamente causada por neuronas que carecen por completo de subjetividad. Mas nada ni nadie puede dar lo que no tiene y de lo que por principio ha sido expresamente privado (aunque se olvide después ese acto de abstracción), y de la nada nada surge.

Ese es el segundo elemento que muestra la unilateralidad y parcialidad del análisis determinista del experimento de Libet. Es un momento que no ha sido visto, ni puede serlo desde la óptica científica, a saber, la conciencia o subjetividad prerreflexiva del cuerpo, debido también a la identificación que se hace de subjetividad y conciencia reflexiva.

\section{CONCLUSIÓN: OTRA INTERPRETACIÓN DEL EXPERIMENTO DE LIBET}

Ahora tenemos los elementos mínimamente necesarios para comprender qué ha ocurrido en el experimento de Libet. Encontramos en él cuatro momentos esenciales, y no sólo tres como se contemplaba en la interpretación determinista, uno de ellos incluso no plenamente entendido.

14 AT, III, 684-685. 
El primero es la planificación previa y consciente del experimento en la idealidad del pensar por parte de los científicos actuante después también en los sujetos experimentados, que han comprendido lo que hay que hacer. Es una idealidad que determinará todos los elementos materiales y las acciones reales que se llevarán a cabo para realizarla. Es ese concepto, y no las neuronas de los sujetos experimentados, el que dispone todo el proceso, lo controla, decide cuándo empieza, qué hay que hacer con ese botón, cuándo acaba, lo valora y lo comprende. Esto no ha sido tenido en cuenta en el análisis determinista.

En segundo lugar, esa planificación o concepto o fin se hace cuerpo, se objetiva, mediante la subjetividad prerreflexiva del cuerpo, del cuerpo de los que toman parte en el experimento. Esta subjetividad forma una unidad con la objetividad del cuerpo e inicia con él y en él el movimiento, primero de forma prerreflexiva, o inconsciente, inconsciente desde el punto de vista de la conciencia reflexiva, pero consciente y sentida en la conciencia prerreflexiva, desde la perspectiva de la primera persona, que tiene su objetivación adecuada en las neuronas de los sujetos experimentados que han de apretar un botón. Ese momento es necesariamente prerreflexivo, pues sólo ahí se da la unión sujetoobjeto, que es únicamente donde la acción libre y su concepto de fin puede tomar cuerpo. Ni la conciencia reflexiva por sí sola es capaz de producir un movimiento objetivo, ni ningún objeto desprovisto de toda subjetividad puede engendrar la conciencia. En el análisis objetivo no se ve ese momento subjetivo prerreflexivo, pues nada subjetivo cae bajo la observación objetiva y objetivante de la ciencia. En consecuencia, el científico tiene necesariamente una visión parcial de lo que ahí ocurre, y no alcanza a percibir la otra parte que él excluye por principio metodológico.

Ese inicio prerreflexivo neuronal subjetivo-objetivo, que pone en marcha los motores para llegar a la acción física, logra poco después hacerse reflexivamente consciente como "decisión de apretar el botón», que es el tercer momento de este proceso. Esa conciencia no puede proceder de algo meramente objetivo (ninguna conciencia es explicable así), pues tiene otro modo de ser, sino de la subjetividad prerreflexiva que se pone en marcha para ejecutar el experimento proyectado y que por tanto a su vez sigue los dictados de esa programación ideal, reflexiva y científica. Lo que viene después de la actividad neuronal no es por tanto la decisión programada, consciente y reflexiva de hacer el experimento y apretar el botón, que es la que comanda todo el proceso, sino sólo la conciencia de haberlo ejecutado en ese momento. Por esto, porque para actuar físicamente hay que recurrir a la unión primigenia de objeto-sujeto que tiene lugar en la conciencia prerreflexiva y corporal, es por lo que la actividad neuronal sucede necesariamente en un tiempo anterior al de la conciencia reflexiva y subjetiva de haberlo ejecutado y de estar llevándolo a cabo o de haber realizado el movimiento, pues esta requiere de nuevo la distinción (posterior) entre sujeto y objeto. Esta conciencia reflexiva sí depende de la conciencia prerreflexiva, que forma una unión sintética con la actividad de las neuronas, tal y como aparece en el experimento de Libet. 
El cuarto momento es el de la ejecución física de lo programado idealmente y decidido, el apretar físicamente el botón con el dedo. En la conciencia reflexiva este cuarto momento queda diferenciado de la conciencia subjetiva de querer actuar, que era el tercer momento. Es decir, el segundo momento, el de la conciencia prerreflexiva o unión sujeto-objeto, da lugar en el ámbito de la conciencia reflexiva al tercer y cuarto momento, a saber, al desdoblamiento o diferenciación entre el querer meramente subjetivo (tercer momento) y lo objetivo o acción física de apretar el botón (cuarto momento). Ese querer meramente subjetivo del tercer momento no ha sido ciertamente (y en esto insiste la interpretación determinista) el que ha causado el segundo, la actividad de las neuronas, ni tampoco el cuarto (el acto físico de apretar el botón), sino que ambos (el tercero y el cuarto) son el mismo acto visto desde las dos perspectivas cuya diferenciación le resulta necesaria a la conciencia reflexiva: la subjetiva y la objetiva. La idealidad o subjetividad o libertad que ha dado lugar a la actividad de las neuronas, y a que éstas actúen así y no de otra manera, hay que situarlo en el primer y segundo momentos, a saber, en la conciencia prerreflexiva que la acompaña y en la ideación del experimento que la precede.

La libertad no es un fantasma, ni la subjetividad un mero espectador engañado de lo que cree que son sus acciones, aunque a veces pueda suceder así por falta de reflexión o por miedo a la libertad. Somos libres, no son las neuronas las que determinan nuestros actos conscientes, sino que ellas se limitan a objetivar y dar cuerpo a lo programado (sí que inician los actos reflejos, por ejemplo cuando me pinchan en el brazo y lo muevo en la dirección contraria). El análisis de lo que sucede en el experimento de Libet así lo atestigua. No el análisis parcial, que olvida cosas y no ve otras, y que por eso conduce al determinismo, sino un análisis completo de todos los elementos y momentos allí implicados. Este análisis muestra que somos actores y agentes responsables de lo que planificamos y ejecutamos con nuestro cuerpo vivido y sentido como nuestro. Somos, claro está, limitadamente actores de nuestras vidas, todo lo real es limitado. Sólo la fantasía y las ensoñaciones pueden carecer de límites. Hay muchos acontecimientos que no dependen de nosotros en cuanto sujetos conscientes y libres, incluso hechos que ocurren en o por nuestro propio cuerpo. Pero de algunos sucesos podemos y debemos decir: «Yo lo he hecho, yo soy el responsable de lo sucedido, de ese fenómeno del mundo».

Facultad de Filosofía,

Jacinto Rivera de Rosales

UNED, Madrid.

jrivera@fsof.uned.es

[Artículo aprobado para publicación en octubre de 2016]. 
